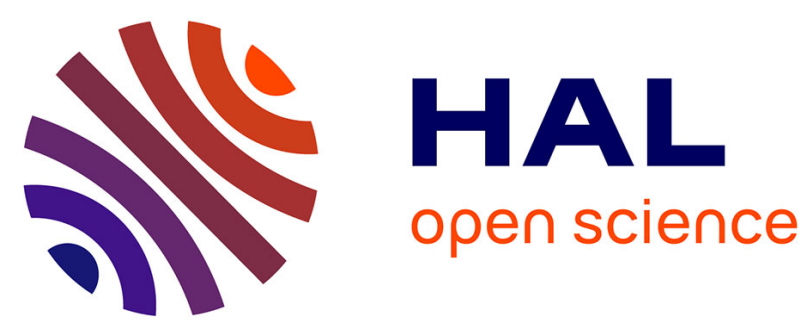

\title{
Adaptation to an uncertain climate change: cost benefit analysis and robust decision making for dam dimensioning
}

\author{
Hypatia Nassopoulos, Patrice Dumas, Stéphane Hallegatte
}

\section{- To cite this version:}

Hypatia Nassopoulos, Patrice Dumas, Stéphane Hallegatte. Adaptation to an uncertain climate change: cost benefit analysis and robust decision making for dam dimensioning. Climatic Change, 2012, 114 (3-4), pp.497-508. 10.1007/s10584-012-0423-7 . hal-00719113

HAL Id: hal-00719113

https://hal-enpc.archives-ouvertes.fr/hal-00719113

Submitted on 7 Apr 2015

HAL is a multi-disciplinary open access archive for the deposit and dissemination of scientific research documents, whether they are published or not. The documents may come from teaching and research institutions in France or abroad, or from public or private research centers.
L'archive ouverte pluridisciplinaire HAL, est destinée au dépôt et à la diffusion de documents scientifiques de niveau recherche, publiés ou non, émanant des établissements d'enseignement et de recherche français ou étrangers, des laboratoires publics ou privés. 


\title{
Adaptation to an uncertain climate change: cost benefit analysis and robust decision making for dam dimensioning
}

\author{
Hypatia Nassopoulos ${ }^{* \dagger} \quad$ Patrice Dumas ${ }^{\ddagger}$ \\ Stéphane Hallegatte ${ }^{\S}$
}

March 2012

The final publication is available at www.springerlink.com http://link. springer.com/article/10.1007/s10584-012-0423-7.

\begin{abstract}
Climate models project large changes in rainfall, but disagree on their magnitude and sign. The consequences of this uncertainty on optimal dam dimensioning is assessed for a small mountainous catchment in Greece. Optimal dam design is estimated using a Cost-Benefit
\end{abstract}

*nassopoulos@centre-cired.fr, Pôle de Recherche en Economie et Gestion (PREG), Département d'Économie École Polytechnique 91128 Palaiseau Cedex, France. Centre National de Recherche sur l'Environnement et le Développement (CIRED) Jardin Tropical - 45 bis, avenue de la Belle Gabrielle 94736 Nogent-sur-Marne Cedex, France.

${ }^{\dagger}$ This research study was financed by the European Union under the integrated project CIRCE. We would like to thank Jean-Louis Dufresne from the LMD laboratory for his valuable advice on climatic data extraction and Maria M. Mimikou Professor of NTUA, for letting us use the figure of the general plan of the area. We would also like to thank Yannis Kouvopoulos from Public Power Corporation of Greece for his encouragement, ITIA research team from the National Technical University of Athens Faculty of Civil Engineering for the reports on historical runoff and Professor Athanasios Loukas and Lampros Vasiliades from University of Thessaly, Department of Civil Engineering, Volos for their indications on data sources.

${ }^{\ddagger}$ Centre National de Recherche sur l'Environnement et le Développement (CIRED). Centre de Coopération Internationale en Recherche Agronomique pour le Développement (CIRAD) M Avenue Agropolis, 34398 Montpellier Cedex 5, France

${ }^{\S}$ Centre National de Recherche sur l'Environnement et le Développement (CIRED). École Nationale de la Météorologie (Météo-France), 42, avenue Coriolis, 31057, Toulouse, France 
Analysis (CBA) based on trends in seasonal temperature and precipitations from 19 IPCC-AR4 climate models driven by the the SRES A2 emission scenario. Optimal reservoir volumes are modified by climate change, leading to up to 34-percent differences between optimal volumes. Contrary to widely-used target-based approaches, the CBA suggests that reduced rainfall should lead to smaller water reservoirs. The resulting change in the Net Present Value (NPV) of water supply is also substantial, ranging from no change to a large 25 percent loss, depending on the climate model, even assuming optimal adaptation and perfect foresight. In addition, climate change uncertainty can lead to design errors, with a cost ranging from 0.3 percent to 2.8 percent of the NPV, depending on site characteristics. This paper proposes to complement the CBA with a robust decision-making approach that focuses on reducing design-error costs. It also suggests that climate change impacts in the water sector may reveal large, that water reservoirs do not always provide a cost-efficient adaptation strategy, and that alternative adaptation strategies based on water conservation and non-conventional water production need to be considered.

Keywords: Optimal dam dimensioning, Climate Change, Adaptation, Uncertainty

JEL classification: Q25, Q54, L95

\section{Introduction}

According to the IPCC (2007), global mean temperature could increase by between 1 and $6^{\circ} \mathrm{C}$ over this century. This warming would lead to multiple and heterogeneous changes in local climates. Some locations would experience larger warming (e.g., the polar regions) than others (e.g., the southern hemisphere). Some locations would receive more precipitations while others would become drier. These local changes will have many consequences, in many economic sectors, and will make it necessary to implement adaptation actions.

In some sectors, adaptation can be reactive while in others, it needs to be anticipated especially for investments with very long timescales (Hallegatte et al., 2007). Anticipation necessitates detailed information on how local climates will change. However, for various reasons detailed in Hallegatte (2009), future local climates are uncertain: there is still a large uncertainty on future greenhouse gas emissions, on the reaction of global temperature to changes in greenhouse gas concentrations and on how a change in global mean temperature would translate into changes at the local scale, the last being 
particularly important for adaptation in water management. To cope with this situation of increased uncertainty, Hallegatte (2009) proposed to follow Lempert and Collins (2007); Groves and Lempert (2007) and to implement robust anticipated adaptation strategies that aim at reducing vulnerability in the largest possible range of climate changes.

This article applies this idea to dam dimensioning in the water management sector, a sector that is particularly sensitive to climate conditions. In addition, in this sector, investments like dams are made for very long time, thus requiring the taking into account of future changes. With climate change, hydro-climatic parameters would be modified, affecting runoff, soil moisture and groundwater level. On account of quantitatively and qualitatively altered water resources and affected water consumption, the conception of hydraulic infrastructure will have to be revised.

Previous studies have investigated this issue. Frederick and Schwarz (1999) investigate the change in renewable water supplies for the United States, focusing on changes in mean inflow. They determine least cost management scenarios to balance change in evaporation from surfaces of man made reservoirs and protect instream flows. To do so, conservation measures appear to be less expensive than increases in supply. They use two climate change scenarios, and obtain widely different least-cost strategies, stressing the importance of uncertainty in future climate change. Vogel et al. (1997) use simplified yield-storage relations to determine the sensitivity of complex reservoir systems for river basins under climate change. Still at the regional level, in China, Kirshen et al. (2005) go further and determine the storage capacity needed to meet demand at the highest possible level of reliability, taking into account the variability in precipitation and inflows. To do so, they use the modified sequent-peak method, and evaluate the associated costs using simplified unit-cost relations based on geophysical characteristics. More recently, Ward et al. (2010) provided an estimation of global and regional adaptation costs to reduced water availability. This study assesses the cost of providing enough water to satisfy the projected industrial and domestic water demands in 2050, using additional water storage and non-conventional water production. According to their results, global storage capacity is projected to increase significantly by $34-36 \%$ over the period 2010-2050. Estimated adaptation costs are of $\$ 12$ bn per year, with almost $90 \%$ of these costs in developing countries.

At a local level, some studies also try to assess the implication of climate change for reservoir dimensioning. For example, Robinson (1997) determines the maximum draw from a reservoir, and, hence, the minimum dam size necessary to maintain a continuous energy generation under climate change in some locations of the USA. A different methodology, based on the integrated 
economic-engineering optimization model CALVIN (Tanaka et al., 2006) is used to study the ability of California water supply system to adapt to long term climatic and demographic changes. This methodology allows for the determination of shadow values for infrastructure capacities and conveyance capacities. The study shows that, in that case, conveyance expansion is the most relevant option.

In response to a change in the precipitation regime, the variability of water supply can increase or decrease. To assess the performance of hydraulic infrastructures along this dimension, the reliability is a commonly used indicator. According to Koutsoyiannis (2005), the reliability of a reservoir is the probability that the reservoir will accomplish a needed function, for example demand satisfaction, over a specific time period under stated conditions. The studies presented above allow the determination of the dimensioning or cost associated with maintaining a fixed level of reliability. Mimikou et al. (1991b); Mehrotra (1999) also determine water reservoir dimensions to reach different reliability targets.

Equivalently, one can consider the change in water demand that can still be satisfied at an unchanged reliability level. For instance, a reduction in precipitation with unchanged water demand can lead to more frequent supply interruption, i.e. the water demand that is satisfied at an unchanged reliability level is lower. Sometimes, accepting a change in available water can be more efficient than trying to keep up with climate change with different infrastructure. Brikowski (2008) shows that for some reservoirs in the Great Plains of USA, due to groundwater mining and climate change, the decline in streamflow leads to a profound inefficiency of reservoirs: negative water budgets even become common as over half of the water flowing into the reservoirs evaporates.

It is not always possible nor efficient to modify the storage capacity of water reservoirs to maintain unchanged the reliability of water supply, and a change in demand can also be considered. Instead of a dimensioning based on a target, cost-benefit analysis may be used to determine the optimal dimension of a dam, taking into account demand and supply changes. In O'Hara and Georgakakos (2008), the effectiveness of storage capacity expansion is assessed for the water supply of San Diego in the US, and an optimal investment policy is determined. In this study, several capacity expansion increments are tested, and a valuation of demand and water imports is performed. Three climate models are used, and a sensitivity analysis is also conducted on population change and plausible model parameter values. The expansion problem is then solved as a recursive mathematical programming.

We find in the literature two approaches, one that determines the size or cost of infrastructure based on a target in water delivery, and one that uses 
cost-benefit analysis to compute the optimal infrastructure design, taking into account the costs of construction and operation and the benefit from water demand satisfaction. Here, we follow the second approach and use a cost-benefit analysis to determine dam dimensions.

A first contribution of this paper is to show that the cost-benefit analyses and target demand approaches lead to opposite results: with decreasing rainfall, target based methodologies lead to larger dams, while cost-benefit analyses lead to smaller dams. To investigate this issue as well as the role of climate uncertainty, a simple model of dam dimensioning under climate change is set up and tested on a small mountainous catchment in Greece, where different climate models from the IPCC lead to different changes in terms of precipitation.

Then we show how using different climate models could lead to very different choices in terms of optimal dimensioning and different net present values (NPV) for the available water. These results highlight the need to use multiple models to avoid potential maladaptation. We also assess the cost of error, and find that this cost is surprisingly low in light of the wide differences in optimal volumes. Then, we discuss alternative strategies to decide about dam dimensioning in the current situation where climate uncertainty at the regional scale is very large. Even though applied to a small catchment, we claim that this work yields insights that are of general relevance for climate change adaptation and water management in a changing climate.

The model is applied to the Pyli basin, a Mediterranean mountainous catchment in northern Greece, which is part of an important water development project for the Acheloos River. According to the IPCC (2007), mean annual warming in the Mediterranean could be more important compared to the other regions and mean annual precipitation could reach $-20 \%$ (see more details on the studied region in section 1 of the Online Resource).

Section 2 presents an overview of the methodology for optimal dam dimensioning under climate change. Section 3 applies this methodology assuming three different reservoir geometries and using 19 climate models simulations from the IPCC. Section 4 concludes and proposes insights on how to make climate-sensitive decisions in the current situation of uncertainty.

\section{Methodology}

This section summarizes the methodology of this study. More details are available in the Online Resource.

First, we assume a stationary climate, before we take into account nonstationarity. Assuming that climate is stationary, the water demand that 
can be satisfied by a water reservoir at a given target reliability level is determined. Reliability is computed using the behavioral method, allowing to numerically compute the water supply level associated with the reliability target. This step is described in details in section 2.1 of the Online Resource.

The downscaling method allowing to determine precipitations and temperatures changes under the stationary climate follows the $\Delta$ methodology. With this method, the climate change signal extracted from General Circulation Models (GCM) is applied to observed climate data. We apply the same seasonal precipitation and temperature changes every year, therefore changes in inter-annual variability are not considered. Potentially important climate change impacts on variability (Schär et al., 2004) are thus disregarded. Intraannual variability changes projected by the models are taken into account through the consideration of two 6-month seasons (summer and winter).

To translate climate-variable changes into runoff changes in a stationary climate, we use the temperature dependent precipitation-runoff magnification factors published by Mimikou and Kouvopoulos (1991). The magnification factor value is determined based on precipitation and temperature change and allows to convert change in precipitation to change in runoff. This change in runoff is then applied to the historical time series with the same monthly runoff change applied each year. It is then assumed that the water demand in a changed climate adjusts to the water supply, which is defined as the amount of water that can be supplied at a given reliability level (here 95\% of the time). The methodology is detailed in Online Resource, section 2.2.

To account for non-stationarity, climate is then modeled as a succession of stationary climates. Because we have only one simulation for each climate model, and because climate models have difficulties to reproduce natural inter-annual and inter-decadal variability, this analysis uses a combination of historical data series and of climate model outputs. Climate models provide the climate change signals (including changes in intra-annual variability), while historical data provide the inter-annual and interdecadal variability (assumed unaffected by climate change). From these climate information, the runoff probability distribution function for one given year is assumed to be the same than the runoff in a stationary climate with the same stable climate characteristics. From this runoff characteristics, the water that can be supplied in a given year with a given reliability is calculated for each year of the period. The precise computation is available in Online Resource, section 2.3 .

Construction costs for a given capacity are determined by considering a valley-shaped reservoir with a rock-filled dam at the entrance of the valley. The cost computation is described precisely in section 3 of the Online Resource. 
The economic benefits of a given demand for a year is set to the discounted value of water, where the quantity of water used is set to the demand in transient climates as described above. The unit water price is considered to be independent of the demand level and grows at the same rate than the economy. Several unit water prices are used. The net present value (NPV) of the water system is set equal to the benefits of water minus the construction costs. The system (water and man-made reservoir) net present value is then maximized in order to determine the optimal dam dimension. The parameter values and the details of computation are described in section 4 of the Online Resource.

\section{Results}

\subsection{Reference case without climate change}

The relationships between dam height, reservoir surface and reservoir volume are in agreement with Georgakakos et al. (1999) with the default parameter set. We also consider other reservoir geometries to investigate model results. The model, indeed, is meant to be generic and this sensitivity analysis highlights how optimal storage capacity choice under climate change may depend on local constraints. Therefore, optimal volumes are computed for different valley lengths, which determine the marginal cost of the reservoir: in a longer valley, a given reservoir volume is achieved with a smaller (and cheaper) dam. The results obtained without climate change are described in detail in section 6 of the Online Resource.

\subsection{Optimal dimensioning under climate change}

Consistently with IPCC (2007) for the Mediterranean region, mean runoff tend to decrease under climate change with changes between $0 \%$ and $-21 \%$. Details on runoff change computation and runoff change for all models are available in the Online Resource, section 5 and Table 8. In the following, changes in optimal volume storage, satisfied demand and economic value relative to a case with no climate change, are presented.

\subsubsection{Optimal Volume}

Figure 1 shows how the water system net present value (NPV) depends on the reservoir volume, for a valley length $10 \mathrm{~km}$ and for three models CNRMCM3 (exhibiting a very important reduction in variability and mean), CSIROMK35 (with a moderate reduction in variability and mean), and 


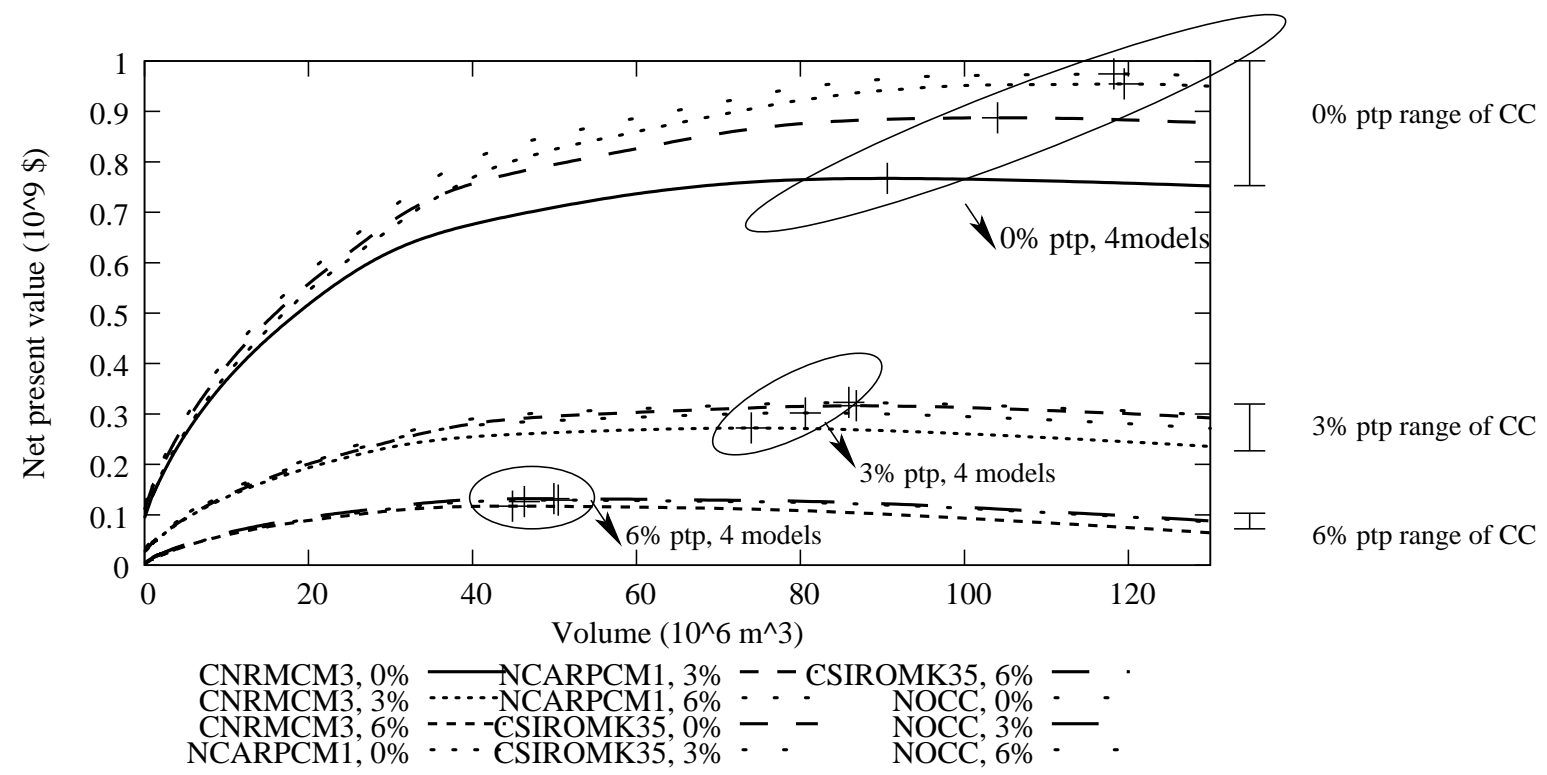

Figure 1: Net present value as a function of reservoir volume. Three models and the no-climate-change case (NOCC) are shown and three rates of pure time preference. The models (CNRMCM3, NCARPCM1 and CSIROMK35) exhibit different changes in variability and mean. The purpose is not to show the precise NPV of each model but to illustrate, beside the usual pure time preference effect (lower NPV and optimal volume), the reduction of NPV difference between models under climate change. Indeed, the NPV range is much larger for a $0 \%$ pure time preference 
NCARPCM1 (with an unchanged mean and an increase in variability). The figure includes the results with a null pure time preference and with a 3 and 6 percent rate of pure time preference (corresponding to a low, medium and high interest rate).

The purpose of this illustration is not to show the precise NPV values but the three groupings (indicated with the three ellipsis) of the four models (CNRMCM3, CSIROMK35, NCARPCM1, no climate change) corresponding to the three pure time preferences $(0 \%, 3 \%, 6 \%)$ and their respective NPV ranges under climate change (indicated with the three vertical bars). This figure shows that a higher discount rate has two consequences: classically, it leads to lower benefits and therefore smaller optimal volumes, but it also diminishes the effect of climate change as the difference of computed NPVs is reduced when the discount rate is higher. This arises simply from the fact that higher discount rate leads to giving less importance on the future, where most of climate change is taking place.

The minimum and maximum change in optimal volume obtained by the maximization of the NPV is shown in Table 1, as a percentage of the case with no climate change for three valley lengths and three pure time preferences. The change is more significant when the pure time preference is low. Optimal volume changes range from $-34 \%$ up to $+2 \%$, indicating the large uncertainty. More detailed results for all the IPCC models in Table 3 of the Online Resource show that less runoff conduces to smaller volumes. Hence, lower rainfall is not compensated through increased water storage in an optimal adaptation strategy using cost-benefit analysis, which is in contrast with the result obtained with the demand target methodology (Ward et al., 2010; Mimikou et al., 1991b).

These results depend on the hypothesis that the unit value of water is constant. When water is scarcer, the increase in unit water value could increase the benefits of building a bigger reservoir and lower the differences in size. Here, since the unit value of water do not change, it is not beneficial to bear the costs of capturing an additional part of the smaller water quantity that is available.

Different geometries do not lead to large differences in the percentage change of optimal volumes compared with the no climate change optimal capacities (for each combination of pure time preference and climate change model). This result stems from the fact that changes in mean runoff, standard deviation and winter runoff are rather well correlated. This correlation could explain the comparable percent change of optimal volumes, whether winter runoff, inflow variability or mean runoff is the major driver of the optimal volume. It is interesting to note that the presence of a medium or large size dam gives more importance to total annual precipitation change than to 
seasonal changes. For instance, the change in summer precipitations may be different between climate models, but this does not affect the dam dimensioning or the demand satisfaction because a small reservoir refills mostly in winter and a big reservoir is only affected by inter-annual variability change.

The water value has an effect on the optimal volume, as shown in Table 6 of Online Resource where three water values are compared, although it does not change the results in qualitative terms.

\subsubsection{Satisfied demand}

The change in satisfied demand at the end of the period of 70 years is much less influenced by the pure time preference, as shown on Table 1. This is obvious for a long valley: in that case the reservoir is very big for all pure time preference values, and most of the variability is captured. Therefore, the change in satisfied demand simply follows the change in mean runoff.

An interesting result of this analysis is that - in an optimal adaptation scenario - the reduction in rainfall is not compensated by larger reservoirs. On the opposite, the optimal reservoir is smaller in a drier climate, and the satisfied demand is significantly reduced. In practice, the reduction in satisfied demand is larger than the reduction in runoff with a fixed water value. Optimal adaptation does not maintain water availability.

\subsubsection{Net present value}

The change in net present value takes into account the reservoir size, such that smaller reservoirs lead to lower costs, and the change in satisfied demand. It also integrates what happens in the first years with limited climate change and the potentially important changes in satisfied demand at the end of the period. Net change in NPV is relevant, because it corresponds to the cost of climate change with optimal adaptation taken into account.

Minimum and maximum percent changes in net present value are shown on Table 1 for three valley lengths and three pure time preferences. The change in NPV with climate change may be substantial with low discounting, in case of an important reduction of runoff. Losses can reach up to 25 percent of the net present value of the water system without climate change. Discounting changes the percentages, but the differences remain, with a maximal loss of 12 percent with a $6 \%$ pure time preference. Detailed results for all models are available in Online Resource.

Climate change may even make the reservoir undesirable. The net benefit of the dam may indeed become negative due to climate change for the smallest water price. If water price is low, and with an intermediate valley length of 
Table 1: Ranges of percent changes in optimal volume storage, satisfied demand and net present value (NPV) for three valley lengths and three pure time preferences

\begin{tabular}{l|ccc|ccc|ccc}
\hline Reservoir length & \multicolumn{3}{|c}{$4 \mathrm{~km}$} & \multicolumn{3}{c}{$10 \mathrm{~km}$} & \multicolumn{3}{c}{$20 \mathrm{~km}$} \\
Pure time preference & $0 \%$ & $3 \%$ & $6 \%$ & $0 \%$ & $3 \%$ & $6 \%$ & $0 \%$ & $3 \%$ & $6 \%$ \\
\hline min. volume change & $-23 \%$ & $-12 \%$ & $-12 \%$ & $-23 \%$ & $-14 \%$ & $-10 \%$ & $-34 \%$ & $-13 \%$ & $-7 \%$ \\
max. volume change & $2 \%$ & $2 \%$ & $0 \%$ & $1 \%$ & $1 \%$ & $1 \%$ & $0 \%$ & $0 \%$ & $1 \%$ \\
\hline min. demand change & $-45 \%$ & $-46 \%$ & $-49 \%$ & $-45 \%$ & $-44 \%$ & $-45 \%$ & $-46 \%$ & $-44 \%$ & $-44 \%$ \\
max. demand change & $0 \%$ & $0 \%$ & $0 \%$ & $0 \%$ & $0 \%$ & $0 \%$ & $0 \%$ & $0 \%$ & $0 \%$ \\
\hline min. NPV change & $-25 \%$ & $-21 \%$ & $-21 \%$ & $-23 \%$ & $-18 \%$ & $-14 \%$ & $-23 \%$ & $-16 \%$ & $-12 \%$ \\
max. NPV change & $0 \%$ & $0 \%$ & $0 \%$ & $0 \%$ & $0 \%$ & $0 \%$ & $0 \%$ & $0 \%$ & $0 \%$ \\
\hline
\end{tabular}

$8 \mathrm{~km}$ and a rate of pure time preference of 6 percent, a dam is desirable in the current climate. But with climate change, 18 models lead to an optimal situation without dam, while 1 model favour a situation with a dam.

\subsection{Error costs and robust decision-making}

Climate model uncertainty is here a potential source of error regarding optimal dam dimensioning. Indeed, there is a substantial difference between the optimal heights, and, therefore, a potential for sunk costs, if the realized climate is not consistent with the climate the dam has been designed for. Table 1 shows that, especially for low rates of pure time preference, optimal dimensions differ markedly between different climate change scenarios. For example, with a $10 \mathrm{~km}$ valley and no pure time preference, the optimal volumes varies between $1 \%$ and $-23 \%$ compared with a situation with no climate change.

Assuming - quite unrealistically — that one of the IPCC models is perfectly correct and that the future climate is actually among the climate change scenarios produced by the climate models, we assess the cost of designing the dam using one of the eighteen wrong models ${ }^{1}$. We find a maximal error cost that varies between $0.3 \%$ and $2.8 \%$ of the net present value for the different cases. Details on the error cost assessment are provided in section 9 of the Online Resource, as well as detailed results.

\footnotetext{
${ }^{1}$ Besides the fact that none of the models is perfect in its ability to predict climate change, it is essential to note that we considered here only one emission scenario. The uncertainty on future GHG emissions could be added to this methodology.
} 
A decomposition of the climate change net impacts shows that both adaptation costs and residual impacts decrease with smaller reservoir volumes. Their difference, the net climate change impact, is however quite flat explaining why error costs are low. An illustration of damages decomposition is available in Online Resource, section 10.

Still assuming that one of these models is correct and predicts the actual future climate, the error cost of using the wrong model is shown in the Table 9 of Online Resource, for a $3 \%$ pure time preference rate and a $10 \mathrm{~km}$ valley length. We find that error costs increase regularly with the error in predicting rainfall characteristics.

It has been said that, in the current situation of deep uncertainty on how climate will change, using scenario analysis and robustness criteria was more adequate than cost-benefit analysis; see for instance Lempert and Collins (2007); Groves and Lempert (2007); Hallegatte (2009), and applications to water management in Groves et al. (2007); Dessai (2005); Dessai and Hulme (2007). In the current analysis, it is possible to look for robustness by designing the dam using the volume with which the maximum error cost is the smallest (a minimax approach). Looking at the corresponding models, one find that two models have a maximum error cost that is the smallest, i.e. GFDLCM20 and CSIROMK35 (with a maximal error cost of 0.4 percent). The cost benefit analysis shows that this choice is robust, a result which is not really surprising since the error cost is quite small.

\section{Conclusion}

\subsection{Summary}

This analysis shows that climate change influences in a significant manner the optimal dimensioning of water reservoirs. Since climate change is uncertain, optimal reservoir design is also uncertain. For instance, for a $10 \mathrm{~km}$ valley length with no discounting, the optimal reservoir volume varies between 1 and -23 percent compared with a situation with no climate change, depending on the climate model used. Importantly, our analysis suggests that the reduction in rainfall should lead to building smaller dams and that reduced water availability can not be cost-effectively compensated by more water storage in a setting where the unit value of water is considered to be independent of demand.

There is therefore a potential for sunk-costs, in case a large reservoir is constructed while actual climate change finally calls for a smaller reservoir. Correspondingly, a small reservoir may be constructed, in spite of a potential 
for satisfying a larger water demand. In our case, the costs associated with these errors are not large compared with the net present values differences between scenarios, as they lie between 0.3 percent (with a long valley and a high discount rate) and 2.8 percent (with a short valley and no discounting). Optimums are flat and therefore not very sensitive to the volume chosen in the end.

The net present value of water resources, however, can be substantially affected by climate change: depending on the model, the change in NPV ranges from no change to a reduction of 25 percent (without discounting) or 12 percent ( 8 percent discounting, if $2 \%$ economy growth rate and unit income elasticity are assumed) compared with a situation without climate change. This is a very large negative impact of climate change, even assuming optimal adaptation and perfect foresight.

Consequently, although low error costs is good news for dam dimensioning, this also means that adaptation measures are not always effective to mitigate climate change impacts in the water sector. Adaptation policies need to further focus on how to cope with reduced water resources (e.g. reduced water consumption, non-conventional water production), in addition to maintenance of water resources through increased water storage.

\subsection{Conclusion on adaptation decision making}

Since the optimal net present value is very flat, a cost-benefit analysis appears not to be very useful to discriminate against the different volumes, in the case studied here. This questions the use of cost-benefit analysis to determine the design of the dam, a demand target could be more discriminatory. The net present value resulting from the cost-benefit analysis, however, is a good measure of the opportunity to build the dam, since it is not very sensitive to errors in the dam design.

An analysis of possible error costs of choosing one model, when another one finally reveals correct, shows that carrying out the reservoir design with some models minimizes the maximum possible error cost. In absence of better information, and in a robust decision-making framework, we suggest the use of the volume minimizing the maximum error cost. Even if error costs are limited in the illustrative example of this paper, it may not be the case for all investments. In these cases, reducing the error costs may be a viable decision-making approach.

In such a decision-making framework, it is necessary to have as many models as possible, to reduce the likelihood of "missing" a possible outcome of climate change. In such a framework, therefore, the development and use of many climate models in parallel is very important. It also means that 
model development should not necessarily be concentrated on a so-called "best" model.

\subsection{Next steps and research needs}

This approach is incomplete, however, and few additional considerations will have to be taken into account in the future. Including possible postponing of investment before uncertainty is resolved could be an interesting next step in the analysis (Venkatesh and Hobbs, 1999), especially in the case of unfavourable sites (i.e., short valleys and large climate uncertainty).

In case of important reduction of water resources, large investments in sectors demanding water, especially irreversible investments, would be lost, a fact that should be taken into account in our approach. This change could be reflected in a change in the water unit value, with an increasing value when runoff decreases.

Non climatic change related uncertainties could also be considered and change drastically the results, especially changes in demand and in institutional arrangements (Wood et al., 1997; Callaway et al., 2007; O'Hara and Georgakakos, 2008). Other sources of uncertainty (or uncertainty reduction) could also be taken into account. For instance, the transient dynamics and change of inter-annual variability from GCM is not taken in to account, the change in demand under climate change (e.g., in the agriculture sector) are not considered, only one emission scenario is used, other downscaling methods and hydrological models could be tested. Flood control and sedimentation volume change under climate change could also modify the optimal volume.

More importantly, with the aim of the most robust decision, the possibility that all climate models are wrong has to be included in the analysis, leading to even more complexity. Possible solutions include the addition of expert-based climate change scenarios, to account for the boundaries of possible climate changes (e.g., worst case and best case scenarios).

\section{References}

Aftias, M., 1992. Ydreuseis. Ecole Polytechnique d'Athènes Grèce.

Brikowski, T. H., 2008. Doomed reservoirs in Kansas, USA? climate change and groundwater mining on the Great Plains lead to unsustainable surface water storage. Journal of Hydrology 354, 90-101. 
Callaway, J. M., Louw, D. B., Nkomo, J. C., Hellmuth, M. E., Sparks, D. A., 2007. The Berg river dynamic spatial equilibrium model: A new tool for assessing the benefits and costs of alternatives for coping with water demand growth, climate variability, and climate change in the Western Cape. AIACC Working Paper 31.

Dessai, S., 2005. Robust adaptation decisions amid climate change uncertainties. Phd, University of East Anglia, Norwich.

Dessai, S., Hulme, M., 2007. Assessing the robustness of adaptation decisions to climate change uncertainties: A case study on water resources management in the east of England. Global Environmental Change 17, 59-72.

Frederick, K. D., Schwarz, G. E., 1999. Socioeconomic impacts of climate change on U.S. water supplies. Journal of the American Water Resources Association 35 (6), 1563-1583.

Georgakakos, A., Yao, H., Demarchi, C., Mullusky, M., Jan. 1999. Model development for simulation and optimisation of the Western Sterea Hellas hydrosystem, evaluation of management of the water resources of Sterea Hellas. Tech. Rep. 39, Department of Water Resources, Hydraulic and Maritime Engineering - National Technical University of Athens, Athens, phase 3.

URL http://www.itia.ntua.gr/en/docinfo/134/

Groves, D. G., Knopman, D., Lempert, R. J., Berry, S., Wainfan, L., 2007. Presenting uncertainty about climate change to water resource managers - summary of workshops with the inland empire utilities agency. RAND, Santa Monica, CA.

Groves, D. G., Lempert, R. J., 2007. A new analytic method for finding policy-relevant scenarios. Global Environmental Change 17, 17-85.

Hallegatte, S., 2009. Strategies to adapt to an uncertain climate change. Global Environmental Change 19, 240-247.

Hallegatte, S., Hourcade, J.-C., Ambrosi, P., May 2007. Using climate analogues for assessing climate change economic impacts in urban areas. Climatic Change 82 (1-2), 47-60.

URL http://www . centre-cired.fr/spip.php?article238

ICOLD, 1992. Cost impact on future dam design - Analysis and proposals. Vol. 83 of Bulletins. CIGB ICOLD. 
IPCC, 2007. Climate Change 2007 The Physical Science Basis. Cambridge University Press, Cambridge, United Kingdom and New York, NY, USA, contribution of the Working Group I to the Fourth Assessment Report of the Intergovernmental Panel on Climate Change.

URL http://www.ipcc.ch/

Kirshen, P., Mccluskey, M., R., R. V., Strzepek, K., 2005. Global analysis of changes in water supply yields and costs under climate change: a case study in China. Climatic Change 68 (3), 303-330.

Koutsoyiannis, D., 2005. Reliability concepts in reservoir design. In: Lehr, J. H., Keeley, J. (Eds.), Water Encyclopedia, Surface and Agricultural Water. Vol. 4. Wiley New York, pp. 259-265.

URL http://itia.ntua.gr/en/docinfo/538/

Koutsoyiannis, D., Efstratiadis, A., Karavokiros, G., 2002. A decision support tool for the management of multi-reservoir systems. Journal of the American Water Resources Association 38 (4), 945-958.

Koutsoyiannis, D., Roti, S., Tzeranis, J., Xanthopoulos, T., Jun. 1988. Hydrological investigation of the thessalia water basin. Tech. Rep. 7, Department of Water Resources, Hydraulic and Maritime Engineering - National Technical University of Athens, Athens, final Report.

URL http://www.itia.ntua.gr/en/docinfo/246/

Lempert, R. J., Collins, M. T., 2007. Managing the risk of uncertain thresholds responses: comparison of robust, optimum, and precautionary approaches. Risk Analysis 27, 1009-1026.

Loukas, A., Mylopoulos, N., Vasiliades, L., 2007. A modeling system for the evaluation of water resources management strategies in Thessaly, Greece. Water Resources Management 21 (10), 1673-1702.

Mehrotra, R., 1999. Sensitivity of runoff, soil moisture and reservoir design to climate change in central indian river basins. Climatic Change 42, 725-757.

Mimikou, M., Hadjisavva, P., Kouvopoulos, Y., 1991a. Regional effects of climate change on water resources systems. In: IAHS (Ed.), Proceedings of the Vienna Symposium. No. 201. IAHS, pp. 173-182.

Mimikou, M. A., Hadjisavva, P. S., Kouvopoulos, Y. S., Afrateos, H., 1991b. regional climate change impacts: II impacts on water management works. Hydrological Sciences 36 (3), 259-270. 
Mimikou, M. A., Kouvopoulos, Y. S., 1991. regional climate change impacts: I impacts on water resources. Hydrological Sciences 36 (3), 247-258.

MWH, Oct. 2003. Upper San Joaquin river basin storage investigation Montgomery reservoir surface storage option technical appendix to the phase 1 investigation report. Tech. rep., Bureau of Reclamation MidPacific Region, California Department of Water Resources, The California Bay-Delta Authority.

URL www.usbr.gov/mp/sccao/storage/docs/phase1_rpt_fnl/tech_ \%app/08_mont_res_cov-app_b.pdf

Nalbantis, I., Koutsoyiannis, D., Mar. 1997. Upgrading and updating of hydrological information of Thessalia. Tech. Rep. 4, Hydraulic and Maritime Engineering - National Technical University of Athens, Athens, final Report.

URL http://www.itia.ntua.gr/en/docinfo/186/

O’Hara, J. K., Georgakakos, K. P., 2008. Quantifying the urban water supply impacts of climate change. Water Resources Management 22, 1477-1497.

Robinson, P. J., 1997. Climate change and hydropower generation. International Journal of Climatology 17, 983-996.

Schär, C., Vidale, P. L., Lüthi, D., Frei, C., Häberli, C., Liniger, M. A., Appenzeller, C., 2004. The role of increasing temperature variability in European summer heatwaves. Nature 427, 332-336.

URL http://www.vulnerabilitynet.org/OPMS/getfile.php?bn=sei\% project_hotel\&key=1140130200\&att_id=930

Tanaka, S. K., Zhu, T., Lund, J. R., Howitt, R. E., Jenkins, M. W., Pulido, M. A., Tauber, M., Ritzema, R. S., Ferreira, I. C., 2006. Climate warming and water management adaptation for California. Climatic Change.

Venkatesh, B. N., Hobbs, B. F., 1999. Analyzing investments for managing Lake Erie levels under climate change uncertainty. Water Resources Research 35 (5), 1671-1683.

Vogel, R. M., Bell, C. J., Fennessey, N. M., 1997. Climate, streamflow and water supply in the northeastern United States. Journal of Hydrology 198, $42-68$.

Ward, P., Strzepek, K., Pauw, W., Brander, L., Hughes, G., Aerts, J., 2010. Partial costs of global climate change adaptation for the supply of raw 
industrial and municipal water: a methodology and application. Environmental Research Letters 5 (044011), 10.

Wood, A. W., Lettenmaier, D. P., Palmer, R. N., 1997. Assessing climatic change implications for water resources planning. Climatic Change 37, 203228. 


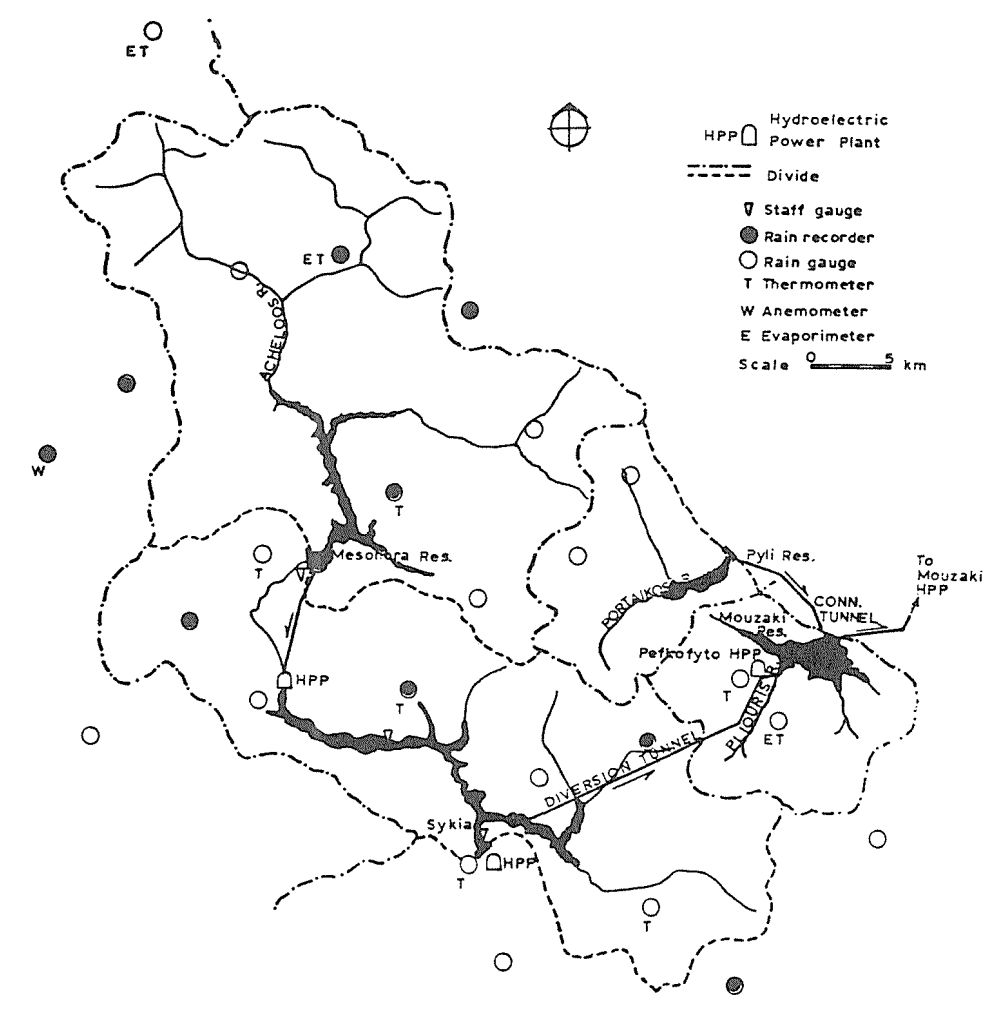

Figure 2: General plan of the study area. Source Mimikou et al. (1991a)

\section{Online supplementary material}

\section{A Study area}

The model is applied to a Mediterranean mountainous catchment in northern Greece, the Pyli basin. The drainage basin is located at Latitude 39.4297 and Longitude 21.6636, at a mean elevation of $800 \mathrm{~m}$ above sea level. The basin has a surface of $134.5 \mathrm{Km}^{2}$. It is one of the four drainage basins that are part of a major water development scheme of the Acheloos River in central Thessaly. The project comprises the construction of four reservoirs that are going to exploit the hypsometric difference for power generation and will also satisfy irrigation demand (Mimikou and Kouvopoulos, 1991; Georgakakos et al., 1999; Koutsoyiannis et al., 2002; Loukas et al., 2007). In this basin, 34 years of historical monthly runoff have been used, taken from Koutsoyiannis et al. (1988, p. 76) and Nalbantis and Koutsoyiannis (1997, p. 31). This data provide important information on runoff variability in the catchment, which 
is one of the basic information needed for dam dimensioning. A monthly time step is used, which is a very common setup in water management studies.

For the Mediterranean region under climate change, according to IPCC (2007), the mean annual warming could reach $2.2-5.1^{\circ} \mathrm{C}$ based on the A1B scenario, an increase which is more marked compared to the rest of the world. In global warming projections for the Mediterranean area there is less uncertainty concerning the sign compared to other regions of the world, however the magnitude and precise localizations of changes differ among the models. Mean annual precipitation will probably decrease on most of the Mediterranean area, with reductions up to $20 \%$ for South Europe, more pronounced contrast in North Africa, and probably shorter rain and snow cover periods. Evaporation increase in combination with precipitation decrease should conduce to low soil moisture and river flow decrease with more water during the winter in snow dominated basins.

\section{B Demand computation in stationary and chang- ing climates}

\section{B.1 Water reservoir dynamics and demand computa- tion}

This section proposes a method to assess the constant water demand that can be satisfied by a water reservoir, at a fixed reliability level and in a stationary climate. To do so, a behavioural method is used to compute the reliability of water supply for all level of water demand and all possible reservoir storage volumes. This relationship is then inverted to obtain the supply associated with a $\Psi$ target reliability.

The $\Psi$ target reliability must be set high enough in order to be able to trigger investments by economic agents which create the corresponding water demand. If the target reliability is not high enough, economic sectors will not rely on the corresponding available water for their activities and the water may not be consumed, and in the longer term, the economic actors will avoid investing in activities requiring water.

We assume a given series of inflow $I_{t}$ into the reservoir, e.g. the historical data series, and a maximal reservoir volume $K$. Then, the supply reliability is determined with a monthly time step.

The annual water demand $\bar{D}$ is converted to a monthly demand $D_{m}$ using monthly coefficients $\phi_{m}$ (in Table 2 ) in order to compute the pattern of water use in the region: $D_{m}=\phi_{m} \bar{D}$. These coefficients are taken from Aftias (1992) 
Table 2: Fraction of annual demand used each month, $\phi_{m}$, here shown in percent, source: Aftias (1992)

\begin{tabular}{cccccccccccc}
\hline OCT & NOV & DEC & JAN & FEB & MAR & APR & MAY & JUN & JUL & AUG & SEP \\
\hline 6 & 6 & 7 & 8 & 9 & 10 & 11 & 11 & 10 & 9 & 7 & 6 \\
\hline
\end{tabular}

and correspond to the observed values for Athens. The sum of all $\phi_{m}$ is equal to one.

Evaporation losses and precipitations over the reservoir are not taken into account, assuming they cancel out. In site uncontrollable losses are also ignored. Simple operating rules are used for the reservoir: (i) if possible, water is withdrawn to satisfy water demand; (ii) all additional water is used to fill the reservoir volume $V_{t}$; (iii) overflow is spilled and cannot be used. As a consequence, the water volume dynamics is given by:

$$
V_{t+1}=\left\{\begin{array}{l}
K, \text { if } V_{t}+I_{t}-\phi_{m} \bar{D}>K \\
0, \text { if } V_{t}+I_{t}-\phi_{m} \bar{D}<0 \\
V_{t}+I_{t}-\phi_{m} \bar{D}, \text { otherwise }
\end{array}\right.
$$

If $V_{t}+I_{t}-\phi_{m} \bar{D}<0$, the monthly water demand cannot be fully satisfied, and the satisfied monthly demand $D_{m}^{s}$ is only equal to $V_{t}+I_{t}$. Otherwise, the demand is fully satisfied and equal to $\phi_{m} \bar{D}$. The reliability of water supply over all periods $T$ of reservoir operation, is equal to the mean value of monthly reliabilities:

$$
R=\frac{\sum_{t}^{T} \frac{D_{m}^{s}}{D_{m}}}{T}
$$

To avoid choosing an initial value for the reservoir fill percentage, a first simulation is carried over with a reservoir initially empty, without calculating reliability. The last value of this simulation is used as starting point for an additional simulation that is used to compute reliability $R_{I, K}(\bar{D})$.

The supply guaranteed with a $\Psi$ target reliability,

$$
S_{\Psi}=R_{I, K}^{-1}(\Psi)
$$

is computed by inverting the reliability function, which is a monotonically decreasing function of the supply target $\bar{D}$, leading to the supply $S_{\Psi}\left(I_{t, t \in[0, T]}, K\right)$. The resolution of equation 3 can only be done numerically.

This method allows the calculation of the water demand that can be satisfied at the $\Psi$ target reliability level, as a function of the water inflow in the reservoir. We need now to assess how these inflows depend on climate conditions. 


\section{B.2 Demand in a changed (stationary) climate}

In this section, we assume an instantaneous and definitive change in climate conditions, but the climate remains stationary. To take into account climate change, the historical runoff data is modified according to model precipitation and temperature changes. To allow for changes in seasonal variability, we consider two seasons: the winter season $w$ from October until March and the summer season $s$ from April until September. We assume that summer temperatures are increased by $\delta T_{s}$ degree and winter temperatures by $\delta T_{w}$ degree. Summer precipitations are multiplied by $1+\alpha P_{s}$ and winter precipitation are multiplied by $1+\alpha P_{w}$. We apply these changes to every year alike, disregarding changes in inter-annual variability. A potentially important impact of climate change on variability, see e.g. Schär et al. (2004), is thus disregarded.

These changes in precipitations and temperatures are translated into changes in runoffs using the historical runoffs $\bar{I}_{t}$ described in section A of the present Online Resource. First, there is an effect of the temperature that changes the runoff even without precipitation change. Classically, there is an increase in winter runoff in case snowmelt increase, and a decrease in summer runoff due to a decrease in remaining snow and an increase in evapotranspiration. Second, a change in rainfall will impact the runoff, this relation being temperature-dependent. In a situation where rainfall is $10 \%$ lower than in the historical data, runoff will be lower than in the historical data by a factor given by a temperature-dependent coefficient multiplied by $10 \%$.

Formally, the runoff change is described by a temperature change factor $A$, added to a precipitation change factor that translates precipitation change to a change in runoff through a "magnification factor" $M$ :

$$
I_{t}=(1+A(\delta T)+M(\alpha P, \delta T) \alpha P) \bar{I}_{t} .
$$

The magnification factor itself depends on precipitation and temperature changes. This parameter summarizes how changes in snow cover, snow melt and evapotranspiration modifies how precipitation influences runoff. In this study, we use the rainfall-runoff magnification factors and temperature change factors published by Mimikou and Kouvopoulos (1991). Linear interpolation and extrapolation is used to determine the magnification factors for all the possible temperature and precipitation changes. In the river basin studied here, the temperature factor $A(\delta T)$ is very small, and is therefore set to 0 .

From these mean winter and summer values, monthly values are computed, by mapping to a sinusoid and rescaling such that the mean seasonal 
change is unchanged. This is done for the magnification factors and the precipitation changes (details are given in section 5.2 of this Online Resource).

Noting $\bar{I}$ the historical runoff, the altered runoff under climate change in season $j$ is:

$$
I\left(\alpha P_{w}, \alpha P_{s}, \delta T_{w}, \delta T_{s}\right)=\bar{I}\left(1+A\left(\delta T_{w}, \delta T_{s}\right)+\alpha P_{j}\left(\alpha P_{w}, \alpha P_{s}\right) \cdot M_{j}\left(\delta T_{w}, \delta T_{s}\right)\right)
$$

with $A\left(\delta T_{w}, \delta T_{s}\right)=0$ for the basin under consideration. Monthly runoff computation is detailed in section 5.3 of this Online Resource.

The altered runoff allows to compute the stationary supply at the $\Psi$ target reliability level $\left(S_{\Psi}\right)$, as explained in the previous section. Then the corresponding demand in a changed climate can be estimated, assuming that demand adjusts to the $\Psi$ target reliability supply.

$$
D_{\Psi}\left(\bar{I}, K, \alpha P_{w}, \alpha P_{s}, \delta T_{w}, \delta T_{s}\right)=S_{\Psi}\left(\bar{I}, K, \alpha P_{w}, \alpha P_{s}, \delta T_{w}, \delta T_{s}\right) .
$$

\section{B.3 Demand in a changing (non-stationary) climate}

Climate change will not be a sudden and permanent shift in climate conditions. Instead, we experience a non-stationary climate with changing climate conditions. Because we have only a few climate simulations and because climate models have difficulties to reproduce natural inter-annual and interdecadal variability, this analysis uses a combination of historical data series and of climate model signals to assess how climate change will modify optimal water infrastructure designs.

For the generation of seasonal precipitation and temperature scenarios, we use the outputs of 19 IPCC AR4 models for the SRES A2 scenario. Monthly precipitation and temperature data from the IPCC AR4 database at the grid point containing the studied river basin are used to compute the seasonal temperature and precipitation changes.

Thirty-year moving averages of the seasonal sums of precipitations and of the seasonal temperature means are computed between 2000 and 2100 . The resulting series are averaged across all the runs for each model, therefore removing the inter-run variability to keep only a mean climate change signal. Then, a linear trend is determined to remove inter-decadal and inter-annual variability, which is uncertain in climate models and can hide the climatechange signal, especially over the short term. This linear trend provides the climate-change parameters $\alpha P_{w}(y), \alpha P_{s}(y), \delta T_{w}(y), \delta T_{s}(y)$ for each year $y$. A period of 70 years is used, corresponding approximately to the reservoir life time. It is worth emphasizing that the resulting time series embed the 
trends in intra-annual variability as obtained from the GCM (through the consideration of two seasons). The time series, on the other hand, discard very uncertain GCM transient dynamics and inter-annual variability.

The demand available each year in a transient climate is computed using the value from a stationary climate determined above, considering that it adjusts to the available resource, and that the available resource in a transient climate is the same than in a stationary climate. For each year of the period, we have a set of climate change parameters, and the demand for this year is then assumed equal to the available demand in a stationary climate with

the same climate change parameters. Formally, the demand satisfied with $\Psi$ target reliability for each year $y$ is:

$$
D_{\Psi}\left(\bar{I}, K, \alpha P_{w}(y), \alpha P_{s}(y), \delta T_{w}(y), \delta T_{s}(y)\right) .
$$

The water that is actually used is:

$$
D(K, y)=\Psi \cdot D_{\Psi}\left(\bar{I}, K, \alpha P_{w}(y), \alpha P_{s}(y), \delta T_{w}(y), \delta T_{s}(y)\right) .
$$

This method allows the assessment of the water demand that can be satisfied with a $\Psi$ target reliability, for each year $y$ and for each climate scenario from the IPCC climate models.

\section{Cost of dam and reservoir}

Construction costs are divided into costs independent of the dam height (spillways, hydropower plants and associated labour costs, land settlements) $C_{f}$, and costs depending on the required storage capacity (height-dependent costs). To determine the height-dependent costs, we first compute the relationship between the storage capacity and the dam height. This relationship determines the dam height required to reach a given capacity. Then the dam cost is determined, using a relationship between dam height and construction cost.

For the reservoir geometry, we consider a valley, with a floor length $L_{v}$ and width $w_{v}$. The valley lateral slopes make an angle $\phi$ with the valley floor. The valley floor is flat and is followed by a slope with an angle $\psi$ with the valley floor. The function linking the storage capacity and the height of the reservoir $h$ is a polynomial function of third degree:

$$
K(h)=\frac{1}{3 \tan (\phi) \tan (\psi)} h^{3}+\left(\frac{w_{v}}{2 \tan (\psi)}+\frac{L_{v}}{\tan (\phi)}\right) h^{2}+L_{v} w_{v} h
$$


Table 3: Geometry and cost parameters

\begin{tabular}{l|l} 
Name & Value \\
\hline$L_{v}$ & $290 \mathrm{~m}$ \\
$w_{v}$ & $81 \mathrm{~m}$ \\
$c_{d}$ & $9 \mathrm{~m}$ \\
$\psi$ & $0.53^{\circ}$ \\
$\zeta$ & $\arctan (1 / 1.5)$ \\
$\phi$ & $19.1^{\circ}$ \\
$C_{f}$ & $3010^{6} \mathrm{US} \$$ \\
$p_{r}$ & $41.6 \$ m^{-3}$ \\
$\rho$ & 0,3 or 6 percent \\
\hline
\end{tabular}

Inverting the above equation, we get the height as a function of the storage capacity $H(K)$.

For the dam itself, we consider a trapezoid rock filled dam at the entrance of the valley. Following ICOLD (1992), for each increase in the dam height of 1 meter, 1.5 meter are required at the base of the dam, therefore the trapezoid angle is $\zeta=\arctan (1 / 1.5)$. Since the dam is in a valley, the crest length depends on the dam height. The crest is considered to be $c_{d}$ meter wide, which could be used, for example, for a road.

The crest length is:

$$
L_{c}(h)=w_{v}+2 \frac{h}{\tan (\phi)}
$$

The volume of the rock filled dam is:

$$
V_{f}(h)=\frac{2}{3 \tan (\zeta) \tan (\phi)} h^{3}+\left(\frac{w_{v}}{\tan (\zeta)}+\frac{c_{d}}{\tan (\phi)}\right) h^{2}+w_{v} \cdot c_{d} \cdot h
$$

The height-dependent cost is considered to be proportional to the dam volume (corresponding with labour, material and groundwork) with a price $p_{r}$. The total cost is thus:

$$
C(K)=C_{f}+p_{r} V_{f}(H(K))
$$

The value of $C_{f}$ is an average of the fixed costs of the different dam options envisaged for the Montgomery Reservoir (MWH, 2003). Even though we assume here that the dam is a rock filled trapezoidal dam, results should 
not be too sensitive to this assumption, since the cost of alternative dams are close to that cost, with possible cost reduction of less than $20 \%$, disregarded here (ICOLD, 1992). Parameters for the default case are shown in Table 3.

\section{Water benefits and net present value}

The water demand satisfied by the reservoir in a transient climate yields an economic benefit which is set to the discounted value of water:

$$
B(K)=\sum_{y} \frac{1}{(1+\rho+\nu g)^{y}} D(K, y) \cdot p_{w}(y)
$$

where $\rho$ is the pure time preference, $g$ is the growth rate of the economy, $\nu$ is the income elasticity, $D(K, y)$ is the water demand that can be satisfied in a transient climate with a $\Psi$ target reliability for each year $y$ and $p_{w}(y)$ is the unit water price. In this equation the classical formulation of interest rate consistent with optimal growth models, $\rho+\nu g$ is assumed.

Here it is considered that the unit water value is independent of the demand level and grows at the same rate than the economy. The current water price is set to $p_{w}(0)$. In this setting, assuming an income elasticity $\nu$ of one:

$$
\frac{p_{w}(y)}{(1+\rho+\nu g)^{y}}=\frac{p_{w}(0)(1+g)^{y}}{(1+\rho+\nu g)^{y}} \approx \frac{p_{w}(0)}{(1+\rho)^{y}}
$$

Hence, equation (12) can be simplified as follows:

$$
B(K)=\sum_{y} \frac{1}{(1+\rho)^{y}} D(K, y) \cdot p_{w}(0)
$$

Water pricing and its relation with water economic value is a delicate issue, with significant contrasts among economic sectors (domestic use, irrigation, hydroelectricity) and institutional arrangements. In general, the potential stress on water resources is not fully taken into account in the determination of tariffs, and the tariffs do not reflect the real value of the water resource.

Here, since unit value of water is considered constant, the cost of scarcity is disregarded. The dependence of the unit value to the demand level is not considered either. This fixed unit water value could be justified if a large alternative source exists with a unit price, not influenced by climate change, which determines this unit value. However, in general, runoff reduction which would lead to lower available water supply for a given reliability level could 
lead to higher water prices and water resources would be reallocated to purposes with higher value.

The optimal dam dimension is determined by the maximization of the net present value of the water system:

$$
N P V=\max _{K}(B(K)-C(K))
$$

$C(K)$, described in section $\mathrm{C}$ of the present Online Resource, is given by the following equation:

$$
C(K)=C_{f}+p_{r} V_{f}(H(K))
$$

Where $H$ is the height of the dam for the reservoir's maximal volume $K$, $V_{f}(H(K))$ the corresponding dam volume, $p_{r}$ the price of labour, material and groundwork per $m^{3}$ of dam volume and $C_{f}$ correspond to the costs that are independent of the dam height. When there is no dam, the net present value is $B(0)$, and the dam is worth constructing if the net present value obtained with the dam is higher than the net present value without dam, i.e. if:

$$
\max _{K}(B(K)-C(K))-B(0)>0 .
$$

The net present value $N P V$ is therefore the value of the full water system including the value of water and not only the value of the man-made reservoir.

In the present study, the $\Psi$ target reliability is set at $95 \%(\Psi=0.95)$. This level can be considered as acceptable for the agricultural sector, since in this sector precipitations may also be used, it is however not acceptable for municipal and industrial supply since which require a reliability level of at least $98 \%$. If, however, an alternative supply and/or drought management plan designed to assist temporary adaptation to reduced supply is established, then a $95 \%$ reliability may be acceptable for all purposes. The unit water demand value is set to about twice of the benefit evaluated for the irrigation sector and one quarter of a typical tariff applied to the domestic sector in Greece i.e. $0.1 \$ . m^{-3}$. Alternative values of $0.05 \$ . m^{-3}$ and $0.4 \$ . m^{-3}$ are also used below, to test the sensitivity to this assumption.

\section{E Runoff change computation}

\section{E.1 Computation of annual runoff change}

The mean annual runoff of the stationary climate corresponding with year $y$ is: 


$$
I^{\text {mean }}(y)=\frac{\sum_{n}\left(I_{n}^{s}(y)+I_{n}^{w}(y)\right)}{N},
$$

where $n$ refers to each of the historical years $N, s$ and $w$ to the summer and winter season.

Then in tables presented in section $\mathrm{G}$ and $\mathrm{H}$ of the Online Resource, the change in annual runoff is

$$
100 \times \frac{\sum_{y} \frac{I^{\text {mean }}(y)-I^{\text {mean }}(0)}{I^{\text {mean }}(0)}}{Y} .
$$

\section{E.2 Seasonal to monthly value computations}

In the following appendices, notation ${ }^{-}$(a bar above a symbol) refers to historical values and`(a hat above a symbol) refers to monthly values. Seasonal values of magnification factors and precipitation changes computed from climatic models outputs are projected to monthly values using a sinusoidal function. Those computations are performed for each month $m$ of season $i(m)$, with $i(m)=s$ for summer, $w$ for winter. In the equation below, $\eta$ denotes a quantity with seasonal means $\eta_{s}$ and $\eta_{w}$, and $\hat{\eta}_{m}$ is the corresponding monthly value. The sinusoidal projection leads to:

$$
\hat{\eta}_{m}=\frac{\eta_{w}-\eta_{s}}{2} \sin \left(\frac{2 \pi m-\pi}{12}\right) \theta_{i(m)}+\frac{\eta_{w}+\eta_{s}}{2}
$$

$\theta_{\tilde{\imath}}$ is determined by setting the seasonal mean computed using monthly values $\hat{\eta}_{m}$ equal to the seasonal value $\eta_{\tilde{\imath}}$ :

$$
\frac{1}{6} \sum_{m / i(m)=\tilde{\imath}}\left(\frac{\eta_{w}-\eta_{s}}{2} \sin \left(\frac{2 \pi m-\pi}{12}\right) \theta_{\tilde{\imath}}+\frac{\eta_{w}+\eta_{s}}{2}\right)=\eta_{\bar{\imath}}, \forall \tilde{\imath}=s, w
$$

Developing the sum leads to

$$
\theta_{w}=\frac{6}{\sum_{m=1}^{6} \sin \left(\frac{2 \pi m-\pi}{12}\right)}=-\frac{6}{\sum_{m=7}^{12} \sin \left(\frac{2 \pi m-\pi}{12}\right)}=\theta_{s}=\theta
$$

The magnification factor for the month $m$ under the changes of year $y$ is therefore set to

$$
\hat{M}_{m}(y)=\frac{M_{w}(y)-M_{s}(y)}{2} \sin \left(\frac{2 \pi m-\pi}{12}\right) \theta+\frac{M_{w}(y)+M_{s}(y)}{2}
$$

Similarly the change in precipitation is:

$$
\hat{\alpha P_{m}}(y)=\frac{\alpha P_{w}(y)-\alpha P_{s}(y)}{2} \sin \left(\frac{2 \pi m-\pi}{12}\right) \theta+\frac{\alpha P_{w}(y)+\alpha P_{s}(y)}{2}
$$




\section{E.3 Runoff monthly values}

With $\bar{I}_{n}^{i}$ the historical seasonal runoff for season $i$, year $n$, the seasonal runoff corresponding with year $y$ climatic changes $I_{n}^{i}(y)$ is:

$$
I_{n}^{i}(y)=\bar{I}_{n}^{i}\left(1+M_{i}(y) \cdot \alpha P_{i}(y)\right)
$$

For each month, with $\hat{\bar{I}}_{n}^{m}$ the historical runoff for month $m$ in year $n$, the modified runoff corresponding with year $y$ climatic changes is set to:

$$
\hat{I}_{n}^{m}(y)=\hat{\bar{I}}_{n}^{m}\left(1+\hat{M}_{m}(y) \cdot \hat{\alpha P} m(y)\right) \beta_{i(m)}(y)
$$

where $\beta_{\tilde{\imath}}(y)$ is a coefficient depending on the season, such that the mean seasonal runoff is equal to the mean sum of the monthly runoffs for the season $\tilde{\imath}$ :

$$
\frac{1}{N} \sum_{n=1}^{N}\left(\sum_{m_{\bar{\imath}}} \hat{I}_{n}^{m}(y) \beta_{\tilde{\imath}}(y)\right)=\frac{1}{N} \sum_{n=1}^{N} I_{n}^{\tilde{\imath}}(y), \forall \tilde{\imath}=s, w
$$

with $m_{\tilde{\imath}} \equiv\{m / i(m)=\tilde{\imath}\}$ the months in season $\tilde{\imath}$.

To compute the $\beta_{\tilde{\imath}}(y)$ coefficients (independent of the year $n$ ), historical seasonal mean $I_{\text {mean }}^{i}=\frac{1}{N} \sum_{n=1}^{N} I_{n}^{i}$ and historical monthly means $\hat{\bar{I}}_{\text {mean }}^{m}=$ $\frac{1}{N} \sum_{n=1}^{N} \hat{\bar{I}}_{n}^{m}$ may be substituted leading to

$$
\beta_{\tilde{\imath}}(y)=\frac{\bar{I}_{\text {mean }}^{\tilde{\imath}}\left(1+M_{\tilde{\imath}}(y) \alpha P_{\tilde{\imath}}(y)\right)}{\sum_{m_{\tilde{\imath}}} \hat{\bar{I}}_{\text {mean }}^{m}\left(1+\hat{M}_{m}(y) \hat{\alpha P_{m}}(y)\right)}, \forall \tilde{\imath}=s, w
$$

Expansion of $\hat{M}_{m}(y)$ and $\hat{\alpha P}{ }_{m}(y)$ leads to

$$
\beta_{\tilde{\imath}}(y)=\frac{\bar{I}_{\text {mean }}^{\tilde{\imath}}\left(1+M_{\tilde{\imath}}(y) \alpha P_{\tilde{\imath}}(y)\right)}{\Gamma_{\tilde{\imath}}^{1}(y) \sum_{m_{\tilde{\imath}}} \hat{\bar{I}}_{\text {mean }}^{m}+\Gamma_{i}^{2}(y) \sum_{m_{\tilde{\imath}}}\left(\hat{\bar{I}}_{\text {mean }}^{m} \sin ^{2}\left(\omega_{m}\right)\right)+\Gamma_{i}^{3}(y) \sum_{m_{\tilde{\imath}}}\left(\hat{\bar{I}}_{\text {mean }}^{m} \sin \left(\omega_{m}\right)\right)}
$$

where:

$$
\begin{gathered}
\omega_{m}=\sin \left(\frac{2 \pi m-\pi}{12}\right) \\
\Gamma_{i}^{1}(y)=\frac{M_{w}(y) \alpha P_{w}(y)+M_{s}(y) \alpha P_{s}(y)+M_{w}(y) \alpha P_{s}(y)+M_{s}(y) \alpha P_{w}(y)+4}{4} \\
\Gamma_{i}^{2}(y)=\frac{M_{w}(y) \alpha P_{w}(y)+M_{s}(y) \alpha P_{s}(y)-M_{w}(y) \alpha P_{s}(y)-M_{s}(y) \alpha P_{w}(y)}{4} \theta^{2}
\end{gathered}
$$




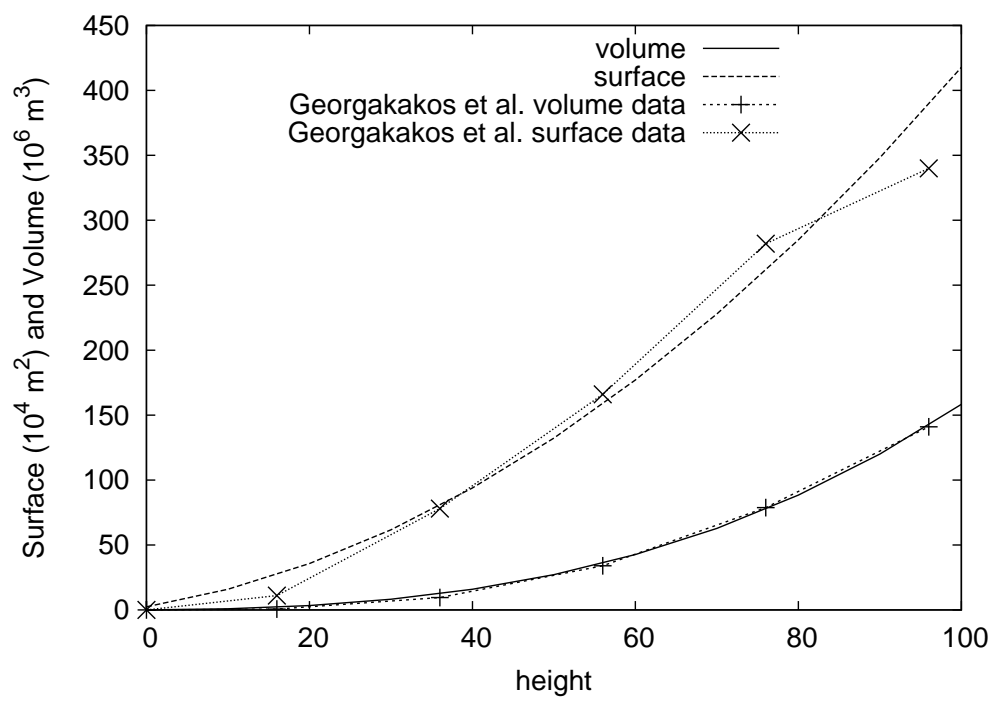

Figure 3: Volume and surface of the reservoir as a function of dam height

$$
\Gamma_{i}^{3}(y)=\frac{M_{w}(y) \alpha P_{w}(y)-M_{s}(y) \alpha P_{s}(y)}{2} \theta
$$

The monthly runoff given by (23) may be negative if $\left(1+\hat{M}_{m}(y) \cdot \hat{\alpha P}_{m}(y)\right)$ is negative, in that case the runoff is set to 0 .

\section{F Reference case without climate change}

With the values on cost and geometry parameters shown in Table 3, the resulting geometry, i.e. the relationship between dam height and reservoir surface and volume is in agreement with Georgakakos et al. (1999), as may be seen on Fig. 3. We also consider other reservoir geometries to investigate model results. The model, indeed, is meant to be generic and this sensitivity analysis highlights how optimal storage capacity choice under climate change may depend on local constraints.

To do so, we consider different valley lengths, which determine the marginal cost of the reservoir: in a longer valley, a given reservoir volume is achieved with a smaller (and cheaper) dam.

Optimal reservoir volumes are computed for three valley lengths of $4 \mathrm{~km}$, $10 \mathrm{~km}$ and $20 \mathrm{~km}^{2}$, no climate change, and several values of the pure time

\footnotetext{
${ }^{2}$ The different geometries are distinguished by different angles $\psi$, larger for a longer
} 
preference.

Short valley. In a catchment with a relatively short reservoir of $4 \mathrm{~km}$, the optimal reservoirs are associated with an extraction of 67 to 89 percent of the mean annual runoff with a reliability of 95 percent, depending on the choice of pure time preference. The frequency of spill varies between 68 percent of the years to more than once a year. The height of the dam varies between 76 and $110 \mathrm{~m}$.

Medium valley. In that case the reservoir length is $10 \mathrm{~km}$, leading to surface and volume consistent with the values reported in Georgakakos et al. (1999). In that case, the optimal reservoir height is between 64 and $89 \mathrm{~m}$, and 77 to $93 \%$ of the mean annual runoff is available with a 95 percent reliability. The frequency of spill varies between 53 percent of the years to once a year.

Long valley. With a reservoir length of 20km, between 89 and 100 percent of the mean annual runoff is extracted, with spill frequencies between 35 and 68 percent and optimal reservoir height between 61 and $93 \mathrm{~m}$. In a long valley, dam building costs are lower and the optimum solution is to capture all (or almost all) intra-annual variability and to reduce the frequency of spillovers close to zero.

\section{G Detailed optimal change results}

The model is implemented in scilab, the code is available upon request. To calculate benefits $B(V)$ and costs $C(V)$ as a function of volume $V$, volumes have been discretized with a step of $0.7 \%$ between each volume. Demand, cost and NPV are computed for all the volumes and all the climate change scenarios. The optimal volume is simply the volume with largest NPV.

Table 4 shows the change of the optimal volume compared with the situation without climate change for 3 valley lengths and 3 pure time preferences.

Table 5 shows the change in satisfied demand at the end of the period of 70 years compared with the situation without climate change for 3 valley lengths and 3 pure time preferences.

Table 6 shows the change of the net present value compared with the situation without climate change for 3 valley lengths and 3 pure time preferences.

valley, and the valley length is found for a dam height of $90 \mathrm{~m}$. The valley floor is flat and is followed by a slope with an angle $\psi$ with the valley floor (see equation 8 ) 
Table 4: Percent change in optimal volume storage relative to a case with no climate change (historic baseline), for three valley lengths, three rates of pure time preference, and 19 IPCC models

\begin{tabular}{|c|c|c|c|c|c|c|c|c|c|c|}
\hline \multirow{2}{*}{$\begin{array}{l}\text { Reservoir length } \\
\text { Pure time preference }\end{array}$} & \multicolumn{3}{|c|}{$4 \mathrm{~km}$} & \multicolumn{3}{|c|}{$10 \mathrm{~km}$} & \multicolumn{3}{|c|}{$20 \mathrm{~km}$} & \multirow{2}{*}{$\begin{array}{l}\text { Stddev } \\
\text { change }\end{array}$} \\
\hline & $0 \%$ & $3 \%$ & $6 \%$ & $0 \%$ & $3 \%$ & $6 \%$ & $0 \%$ & $3 \%$ & $6 \%$ & \\
\hline BCCRBCM20 & -10 & -6 & -3 & -12 & -7 & -7 & -8 & -8 & -2 & -9 \\
\hline CCCMACGCM31 & -9 & -4 & -3 & -15 & -5 & -6 & -16 & -10 & -1 & -9 \\
\hline CNRMCM3 & -23 & -12 & -12 & -23 & -14 & -10 & -23 & -13 & -7 & -21 \\
\hline CSIROMK30 & -14 & -9 & -5 & -16 & -10 & -8 & -11 & -10 & -3 & -13 \\
\hline CSIROMK35 & -10 & -6 & -3 & -12 & -6 & -7 & -9 & -9 & -1 & -9 \\
\hline GFDLCM20 & -10 & -3 & -3 & -14 & -6 & -4 & -25 & -9 & -1 & -10 \\
\hline GFDLCM21 & -17 & -7 & -6 & -21 & -10 & -8 & -34 & -12 & -3 & -16 \\
\hline GISSMODELER & -15 & -9 & -6 & -21 & -10 & -8 & -25 & -11 & -3 & -16 \\
\hline INGVECHAM4 & -17 & -10 & -8 & -22 & -11 & -9 & -17 & -12 & -4 & -18 \\
\hline INMCM30 & -4 & -2 & -1 & -4 & -2 & -3 & -5 & -4 & -1 & -4 \\
\hline IPSLCM4 & -17 & -10 & -7 & -20 & -11 & -8 & -17 & -11 & -4 & -16 \\
\hline MIROC32MEDRES & -5 & -2 & -1 & -6 & -2 & -3 & -8 & -7 & -1 & -5 \\
\hline MIUBECHOG & -17 & -10 & -7 & -18 & -10 & -9 & -14 & -10 & -4 & -15 \\
\hline MPIECHAM5 & -17 & -10 & -7 & -22 & -11 & -8 & -26 & -12 & -4 & -18 \\
\hline MRICGCM232A & -6 & -3 & -1 & -7 & -2 & -4 & -9 & -8 & -1 & -6 \\
\hline NCARCCSM30 & -8 & -4 & -2 & -12 & -4 & -5 & -11 & -9 & -1 & -8 \\
\hline NCARPCM1 & 2 & 2 & 0 & 1 & 1 & 1 & -9 & -1 & 1 & 1 \\
\hline UKMOHADCM3 & -6 & -3 & -2 & -10 & -3 & -4 & -13 & -9 & -1 & -6 \\
\hline UKMOHADGEM1 & 0 & 0 & 0 & 0 & 0 & 0 & 0 & 0 & 0 & -0 \\
\hline
\end{tabular}

\section{H Optimal volume change for different unit water values}

Table 7 shows the change of the optimal volume compared with the situation without climate change for 3 unit water prices and for 2 pure time preferences, for a $10 \mathrm{~km}$ valley length. 
Table 5: Percent change in demand satisfied in the last year, year 70, in percent relative to a case with no climate change (historic baseline), for three valley lengths and three rates of pure time preference

\begin{tabular}{l|ccc|ccc|ccc||c}
\hline Reservoir length & \multicolumn{3}{|c}{$4 \mathrm{~km}$} & \multicolumn{3}{c|}{$10 \mathrm{~km}$} & \multicolumn{3}{c||}{$20 \mathrm{~km}$} & Runoff \\
Pure time preference & $0 \%$ & $3 \%$ & $6 \%$ & $0 \%$ & $3 \%$ & $6 \%$ & $0 \%$ & $3 \%$ & $6 \%$ & change \\
\hline BCCRBCM20 & -15 & -12 & -9 & -16 & -14 & -13 & -15 & -15 & -14 & -8 \\
CCCMACGCM31 & -24 & -25 & -25 & -25 & -24 & -25 & -25 & -24 & -23 & -12 \\
CNRMCM3 & -37 & -33 & -31 & -39 & -37 & -33 & -38 & -38 & -36 & -20 \\
CSIROMK30 & -18 & -15 & -11 & -20 & -18 & -16 & -19 & -19 & -17 & -11 \\
CSIROMK35 & -16 & -13 & -10 & -16 & -15 & -14 & -16 & -16 & -14 & -9 \\
GFDLCM20 & -34 & -37 & -41 & -33 & -33 & -35 & -34 & -33 & -33 & -15 \\
GFDLCM21 & -45 & -46 & -49 & -45 & -44 & -45 & -46 & -44 & -44 & -21 \\
GISSMODELER & -37 & -37 & -37 & -38 & -37 & -36 & -39 & -37 & -36 & -19 \\
INGVECHAM4 & -34 & -32 & -30 & -36 & -34 & -31 & -35 & -35 & -33 & -18 \\
INMCM30 & -8 & -7 & -5 & -8 & -7 & -7 & -8 & -8 & -7 & -4 \\
IPSLCM4 & -32 & -29 & -26 & -33 & -31 & -29 & -32 & -32 & -30 & -17 \\
MIROC32MEDRES & -11 & -10 & -9 & -11 & -10 & -10 & -11 & -11 & -10 & -6 \\
MIUBECHOG & -23 & -19 & -15 & -24 & -22 & -20 & -24 & -23 & -22 & -13 \\
MPIECHAM5 & -41 & -40 & -39 & -42 & -40 & -39 & -42 & -41 & -40 & -20 \\
MRICGCM232A & -13 & -13 & -12 & -14 & -13 & -13 & -14 & -14 & -12 & -7 \\
NCARCCSM30 & -19 & -18 & -17 & -20 & -18 & -18 & -19 & -19 & -18 & -9 \\
NCARPCM1 & -4 & -8 & -11 & -3 & -4 & -6 & -5 & -4 & -4 & -1 \\
UKMOHADCM3 & -19 & -21 & -22 & -19 & -18 & -20 & -20 & -19 & -18 & -9 \\
UKMOHADGEM1 & -0 & -0 & -0 & -0 & -0 & -0 & -0 & -0 & -0 & -0 \\
\hline
\end{tabular}

\section{Error cost assessment}

\section{I.1 Maximal error cost}

To assess the error costs in each situation (three valley lengths and the nodiscounting, 3 or 6 percent pure time preference case), the maximal cost resulting from an error in climate model choice is computed for three volumes:

1. the largest optimal volume among all models,

2. the smallest optimal volume among all models,

3. the optimal volume without climate change. 
Table 6: Percent change in net present value (NPV) in percent relative to a case with no climate change (historic baseline), for three valley lengths, three rates of pure time preference, and 19 IPCC models

\begin{tabular}{|c|c|c|c|c|c|c|c|c|c|c|}
\hline \multirow{2}{*}{$\begin{array}{l}\text { Reservoir length } \\
\text { Pure time preference }\end{array}$} & \multicolumn{3}{|c|}{$4 \mathrm{~km}$} & \multicolumn{3}{|c|}{$10 \mathrm{~km}$} & \multicolumn{3}{|c|}{$20 \mathrm{~km}$} & \multirow{2}{*}{$\begin{array}{l}\text { Runoff } \\
\text { change }\end{array}$} \\
\hline & $0 \%$ & $3 \%$ & $6 \%$ & $0 \%$ & $3 \%$ & $6 \%$ & $0 \%$ & $3 \%$ & $6 \%$ & \\
\hline BCCRBCM20 & -8 & -5 & -4 & -8 & -6 & -4 & -8 & -6 & -4 & -8 \\
\hline CCCMACGCM31 & -14 & -12 & -12 & -13 & -10 & -8 & -13 & -9 & -7 & -12 \\
\hline CNRMCM3 & -22 & -15 & -12 & -21 & -16 & -11 & -21 & -15 & -11 & -20 \\
\hline CSIROMK30 & -11 & -7 & -4 & -11 & -8 & -5 & -11 & -8 & -6 & -11 \\
\hline CSIROMK35 & -9 & -6 & -5 & -9 & -6 & -5 & -9 & -6 & -5 & -9 \\
\hline GFDLCM20 & -19 & -16 & -18 & -17 & -13 & -10 & -17 & -12 & -9 & -15 \\
\hline GFDLCM21 & -25 & -21 & -21 & -23 & -18 & -14 & -23 & -16 & -12 & -21 \\
\hline GISSMODELER & -21 & -17 & -16 & -20 & -15 & -11 & -20 & -14 & -10 & -19 \\
\hline INGVECHAM4 & -20 & -15 & -13 & -19 & -14 & -10 & -19 & -14 & -10 & -18 \\
\hline INMCM30 & -4 & -3 & -3 & -4 & -3 & -2 & -4 & -3 & -2 & -4 \\
\hline IPSLCM4 & -18 & -13 & -11 & -17 & -13 & -9 & -17 & -12 & -9 & -17 \\
\hline MIROC32MEDRES & -6 & -5 & -5 & -6 & -4 & -3 & -6 & -4 & -3 & -6 \\
\hline MIUBECHOG & -13 & -9 & -6 & -13 & -10 & -7 & -13 & -9 & -7 & -13 \\
\hline MPIECHAM5 & -23 & -18 & -17 & -22 & -16 & -12 & -22 & -16 & -12 & -20 \\
\hline MRICGCM232A & -8 & -6 & -6 & -7 & -5 & -4 & -7 & -5 & -4 & -7 \\
\hline NCARCCSM30 & -11 & -9 & -8 & -10 & -8 & -6 & -10 & -7 & -5 & -9 \\
\hline NCARPCM1 & -3 & -4 & -6 & -2 & -2 & -2 & -2 & -1 & -1 & -1 \\
\hline UKMOHADCM3 & -11 & -10 & -10 & -10 & -8 & -6 & -10 & -7 & -5 & -9 \\
\hline UKMOHADGEM1 & -0 & -0 & -0 & -0 & -0 & -0 & -0 & -0 & -0 & -0 \\
\hline
\end{tabular}

For each of these three volumes $V$ and for each climatic model scenario $M$, the cost of error (in percent) is computed as

$$
100 \frac{\max _{v}(N P V(v, M))-N P V(V, M)}{\max _{v}(N P V(v, M))} .
$$

The maximal relative error costs over all models are shown in Table 8 . The error costs are higher in the case of a small valley, up to 2.8 percent of the NPV, while they are small in case of a very long valley, with at most $0.78 \%$. This is consistent with the fact that height-dependent costs are smaller when the valley is long. As a consequence, the NPV is flat around the optimum in the case of the long valley, with a large reservoir and a benefit determined by the available inflow and not too sensitive to the reservoir volume. 
Table 7: Percent change in optimal volume storage relative to a case with no climate change (historic baseline), for a $10 \mathrm{~km}$ valley lengths, two rates of pure time preference, three water values. Water value is in $\$ . m^{-3}$

\begin{tabular}{l|ccc|ccc||c}
\hline Pure time preference & \multicolumn{3}{|c}{$0 \%$} & \multicolumn{3}{c||}{$6 \%$} & Runoff \\
Water value & 0.05 & 0.1 & 0.4 & 0.05 & 0.1 & 0.4 & change \\
\hline BCCRBCM20 & -5 & -12 & -15 & -7 & -7 & -8 & -8 \\
CCCMACGCM31 & -2 & -15 & -9 & -3 & -6 & -10 & -12 \\
CNRMCM3 & -16 & -23 & -28 & -13 & -10 & -16 & -20 \\
CSIROMK30 & -9 & -16 & -20 & -10 & -8 & -11 & -11 \\
CSIROMK35 & -5 & -12 & -14 & -7 & -7 & -9 & -9 \\
GFDLCM20 & -4 & -14 & -9 & 0 & -4 & -11 & -15 \\
GFDLCM21 & -9 & -21 & -13 & -6 & -8 & -14 & -21 \\
GISSMODELER & -9 & -21 & -17 & -8 & -8 & -13 & -19 \\
INGVECHAM4 & -12 & -22 & -23 & -11 & -9 & -14 & -18 \\
INMCM30 & 0 & -4 & -3 & -2 & -3 & -2 & -4 \\
IPSLCM4 & -11 & -20 & -22 & -11 & -8 & -13 & -17 \\
MIROC32MEDRES & 0 & -6 & -4 & -2 & -3 & -4 & -6 \\
MIUBECHOG & -11 & -18 & -23 & -11 & -9 & -12 & -13 \\
MPIECHAM5 & -12 & -22 & -21 & -10 & -8 & -14 & -20 \\
MRICGCM232A & 0 & -7 & -5 & -2 & -4 & -5 & -7 \\
NCARCCSM30 & -2 & -12 & -7 & -4 & -5 & -8 & -9 \\
NCARPCM1 & 10 & 1 & -5 & 0 & 1 & 0 & -1 \\
UKMOHADCM3 & 0 & -10 & -8 & 0 & -4 & -6 & -9 \\
UKMOHADGEM1 & 0 & 0 & 0 & 0 & 0 & 0 & -0 \\
\hline
\end{tabular}

\section{I.2 Error cost for all models}

Assuming that one of the available climate models is correct and predicts the actual future climate, the error cost of using the wrong model is shown in Table 10, for a $3 \%$ pure time preference rate and a $10 \mathrm{~km}$ valley length. Table 9 shows the mapping between indices and model names, as well as changes with respect with a no climate change situation for selected indicators. The indices are used in Table 10. 
Table 8: Maximal error costs in percent for three volumes, the largest volume, the smallest volume and the volume chosen without climate change

\begin{tabular}{l|ccc|cccc|ccc}
\hline Reservoir length & \multicolumn{3}{|c}{$4 \mathrm{~km}$} & \multicolumn{3}{c}{$10 \mathrm{~km}$} & \multicolumn{3}{c}{$20 \mathrm{~km}$} \\
Pure time preference & $0 \%$ & $3 \%$ & $6 \%$ & $0 \%$ & $3 \%$ & $6 \%$ & $0 \%$ & $3 \%$ & $6 \%$ \\
\hline smallest volume & 2.63 & 2.28 & 1.65 & 1.31 & 1.36 & 0.49 & 0.53 & 0.59 & 0.68 \\
no climate change optimal volume & 2.39 & 1.01 & 1.63 & 1.12 & 1.08 & 0.33 & 0.78 & 0.50 & 0.26 \\
largest volume & 2.83 & 1.35 & 1.63 & 1.21 & 1.25 & 0.40 & 0.78 & 0.50 & 0.35 \\
\hline
\end{tabular}

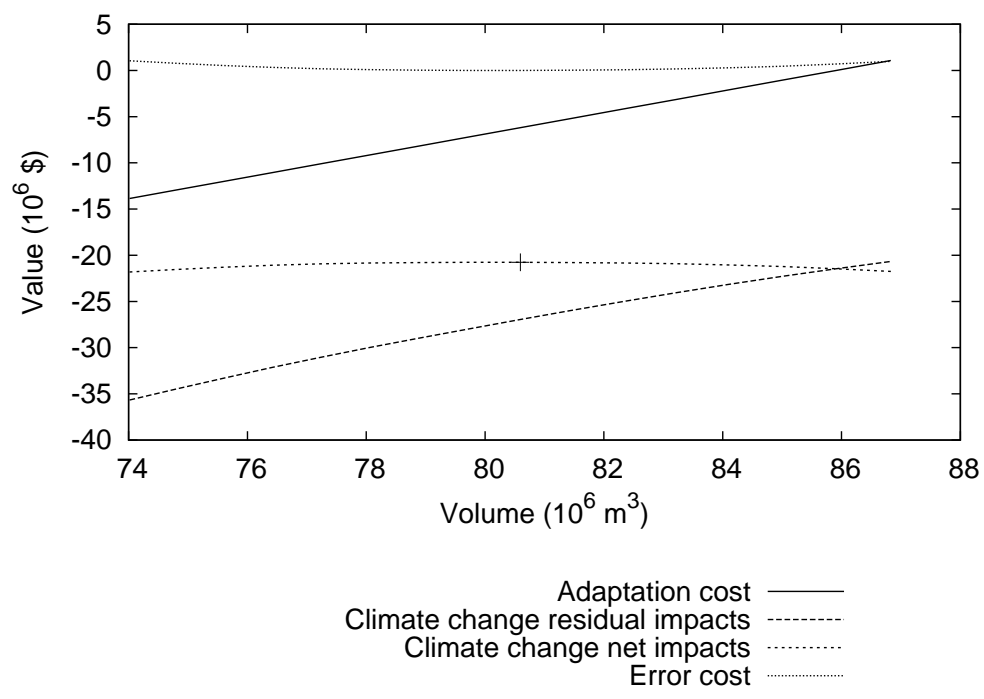

Figure 4: Costs and benefits associated with adaptation of dam dimensioning, for the CSIROMK35 climate change scenario, a pure time preference of 3 percent and a valley length of $10 \mathrm{~km}$. The cross corresponds to the optimal volume. Costs and benefits are shown as a function of the volume of the dam. The adaptation cost is the height-dependent cost of the reservoir. In most cases adaptation costs are negative since reservoirs are smaller with climate change, it is also the case here. The residual impacts are also figured, corresponding with the change in water benefits with climate change and reservoir volume adaptation, compared with the no climate change situation. The residual impacts are also negative because of the decrease in mean runoff compared with the no climate change situation. The net impact of climate change is the difference of water system NPV with respect with the no climate change case. The net impact is quite flat, large, and negative. The error cost is also presented 
Table 9: Climatic models, corresponding indices used in Table 10 and changes in runoff, optimal volume, NPV and standard deviation

\begin{tabular}{l|c|c|c|c|c}
\hline Model name & Index & NPV change & Runoff change & Volume change & Stddev change \\
\hline CNRMCM3 & 3 & -16 & -20 & -14 & -21 \\
IPSLCM4 & 11 & -13 & -17 & -11 & -16 \\
MPIECHAM5 & 14 & -16 & -20 & -11 & -18 \\
INGVECHAM4 & 9 & -14 & -18 & -11 & -18 \\
GISSMODELER & 8 & -15 & -19 & -10 & -16 \\
CSIROMK30 & 4 & -8 & -11 & -10 & -13 \\
MIUBECHOG & 13 & -10 & -13 & -10 & -15 \\
GFDLCM21 & 7 & -18 & -21 & -10 & -16 \\
BCCRBCM20 & 1 & -6 & -8 & -7 & -9 \\
GFDLCM20 & 6 & -13 & -15 & -6 & -10 \\
CSIROMK35 & 5 & -6 & -9 & -6 & -9 \\
CCCMACGCM31 & 2 & -10 & -12 & -5 & -9 \\
NCARCCSM30 & 16 & -8 & -9 & -4 & -8 \\
UKMOHADCM3 & 18 & -8 & -9 & -3 & -6 \\
INMCM30 & 10 & -3 & -4 & -2 & -4 \\
MIROC32MEDRES & 12 & -4 & -6 & -2 & -5 \\
MRICGCM232A & 15 & -5 & -7 & -2 & -6 \\
UKMOHADGEM1 & 19 & -0 & -0 & 0 & -0 \\
NOCC & 20 & 0 & 0 & 0 & 0 \\
NCARPCM1 & 17 & -2 & -1 & 1 & 1 \\
\hline
\end{tabular}

\section{J Decomposition of adaptation costs and ben- efits}

Figure 4 shows the adaptation cost, the error cost, the residual impact and the net climate change impact ${ }^{3}$, as well as their change with dam volumes for the CSIROMK35 climate change scenario, a $10 \mathrm{~km}$ valley length and a $3 \%$ pure time preference. The distinction between adaptation costs and residual impacts is always somehow arbitrary. Here we consider that the adaptation measure is the determination of the optimum size of the dam and the adaptation cost is the cost associated with the change in the dam size, while the residual impact is the difference between the water benefit present value

\footnotetext{
${ }^{3} \mathrm{~A}$ positive impact is a benefit, while a negative impact is a cost.
} 
Table 10: Cost of error, in percentage of net present value, for all models when the optimal volume of another model is chosen. The indices of the models given in Table 9 are in the first column. The same indices are used for the column headers. Each number is the regret of building a dam with the optimal volume calculated using the model in column, if the model in line is finally correct in projecting climate change. The models are ordered by increasing optimal volume, the pure time preference is 3 percent and the valley length is $10 \mathrm{~km}$

\begin{tabular}{|c|c|c|c|c|c|c|c|c|c|c|c|c|c|c|c|c|c|c|c|c|}
\hline & 3 & 11 & 14 & 9 & 8 & 4 & 13 & 7 & 1 & 6 & 5 & 2 & 16 & 18 & 10 & 12 & 15 & 19 & 20 & 17 \\
\hline 3 & 0 & 0.0 & 0.0 & 0.0 & 0.1 & 0.1 & 0.1 & 0.1 & 0.3 & 0.4 & 0.4 & 0.5 & 0.6 & 0.7 & 0.8 & 0.8 & 0.8 & 1.1 & 1.1 & 1.2 \\
\hline 11 & 0.1 & 0 & 0.0 & 0.0 & 0.0 & 0.0 & 0.0 & 0.0 & 0.1 & 0.1 & 0.1 & 0.2 & 0.3 & 0.3 & 0.4 & 0.4 & 0.4 & 0.6 & 0.6 & 0.8 \\
\hline 14 & 0.0 & 0.0 & 0 & 0.0 & 0.0 & 0.0 & 0.0 & 0.0 & 0.1 & 0.2 & 0.2 & 0.3 & 0.3 & 0.4 & 0.5 & 0.5 & 0.5 & 0.8 & 0.8 & 0.9 \\
\hline 9 & 0.0 & 0.0 & 0.0 & 0 & 0.0 & 0.0 & 0.0 & 0.0 & 0.1 & 0.2 & 0.2 & 0.3 & 0.3 & 0.4 & 0.5 & 0.5 & 0.5 & 0.8 & 0.8 & 0.9 \\
\hline 8 & 0.1 & 0.0 & 0.0 & 0.0 & 0 & 0.0 & 0.0 & 0.0 & 0.1 & 0.1 & 0.1 & 0.1 & 0.2 & 0.3 & 0.4 & 0.4 & 0.4 & 0.6 & 0.6 & 0.7 \\
\hline 4 & 0.2 & 0.0 & 0.0 & 0.0 & 0.0 & 0 & 0.0 & 0.0 & 0.0 & 0.1 & 0.1 & 0.1 & 0.2 & 0.2 & 0.3 & 0.3 & 0.3 & 0.5 & 0.5 & 0.6 \\
\hline 13 & 0.1 & 0.0 & 0.0 & 0.0 & 0.0 & 0.0 & 0 & 0.0 & 0.1 & 0.1 & 0.1 & 0.2 & 0.2 & 0.3 & 0.4 & 0.4 & 0.4 & 0.6 & 0.6 & 0.7 \\
\hline 7 & 0.1 & 0.0 & 0.0 & 0.0 & 0.0 & 0.0 & 0.0 & 0 & 0.1 & 0.1 & 0.1 & 0.1 & 0.2 & 0.2 & 0.3 & 0.3 & 0.3 & 0.5 & 0.5 & 0.7 \\
\hline 1 & 0.3 & 0.1 & 0.1 & 0.1 & 0.0 & 0.0 & 0.0 & 0.0 & 0 & 0.0 & 0.0 & 0.0 & 0.0 & 0.1 & 0.1 & 0.1 & 0.1 & 0.2 & 0.2 & 0.3 \\
\hline 6 & 0.4 & 0.1 & 0.1 & 0.1 & 0.1 & 0.1 & 0.1 & 0.1 & 0.0 & 0 & 0.0 & 0.0 & 0.0 & 0.0 & 0.1 & 0.1 & 0.1 & 0.2 & 0.2 & 0.3 \\
\hline 5 & 0.3 & 0.1 & 0.1 & 0.1 & 0.1 & 0.1 & 0.1 & 0.1 & 0.0 & 0.0 & 0 & 0.0 & 0.0 & 0.1 & 0.1 & 0.1 & 0.1 & 0.2 & 0.2 & 0.3 \\
\hline 2 & 0.4 & 0.2 & 0.2 & 0.2 & 0.1 & 0.1 & 0.1 & 0.1 & 0.0 & 0.0 & 0.0 & 0 & 0.0 & 0.0 & 0.0 & 0.0 & 0.0 & 0.2 & 0.2 & 0.2 \\
\hline 16 & 0.5 & 0.2 & 0.2 & 0.2 & 0.1 & 0.1 & 0.1 & 0.1 & 0.0 & 0.0 & 0.0 & 0.0 & 0 & 0.0 & 0.0 & 0.0 & 0.0 & 0.1 & 0.1 & 0.2 \\
\hline 18 & 0.7 & 0.3 & 0.3 & 0.3 & 0.3 & 0.3 & 0.3 & 0.3 & 0.1 & 0.1 & 0.1 & 0.0 & 0.0 & 0 & 0.0 & 0.0 & 0.0 & 0.1 & 0.1 & 0.1 \\
\hline 10 & 0.8 & 0.4 & 0.4 & 0.4 & 0.3 & 0.3 & 0.3 & 0.3 & 0.2 & 0.1 & 0.1 & 0.1 & 0.0 & 0.0 & 0 & 0.0 & 0.0 & 0.1 & 0.1 & 0.1 \\
\hline 12 & 0.7 & 0.4 & 0.4 & 0.4 & 0.3 & 0.3 & 0.3 & 0.3 & 0.1 & 0.1 & 0.1 & 0.0 & 0.0 & 0.0 & 0.0 & 0 & 0.0 & 0.1 & 0.1 & 0.1 \\
\hline 15 & 0.7 & 0.3 & 0.3 & 0.3 & 0.3 & 0.3 & 0.3 & 0.3 & 0.1 & 0.1 & 0.1 & 0.0 & 0.0 & 0.0 & 0.0 & 0.0 & 0 & 0.1 & 0.1 & 0.1 \\
\hline 19 & 1.2 & 0.8 & 0.8 & 0.8 & 0.6 & 0.6 & 0.6 & 0.6 & 0.4 & 0.3 & 0.3 & 0.3 & 0.2 & 0.2 & 0.1 & 0.1 & 0.1 & 0 & 0.0 & 0.1 \\
\hline 20 & 1.3 & 0.8 & 0.8 & 0.8 & 0.6 & 0.6 & 0.6 & 0.6 & 0.4 & 0.3 & 0.3 & 0.3 & 0.2 & 0.2 & 0.1 & 0.1 & 0.1 & 0.0 & 0 & 0.1 \\
\hline 17 & 1.4 & 0.9 & 0.9 & 0.9 & 0.7 & 0.7 & 0.7 & 0.7 & 0.5 & 0.4 & 0.4 & 0.3 & 0.3 & 0.2 & 0.2 & 0.2 & 0.2 & 0.0 & 0.0 & 0 \\
\hline
\end{tabular}


with and without climate change and adaptation, so that losses correspond to negative values. Adaptation cost, which varies in the same direction than residual impacts, increases with the dam volume. In our analysis, adaptation costs are negative, since adaptation leads to smaller, and cheaper, dams. Their difference, the net climate change impact is however quite flat. In that case there is a reduction in available water leading to a negative net impact (i.e. a loss). The error cost, corresponding with the difference in net cost for different volumes, is small, compared with the large adaptation cost of climate change. 